\title{
Teaching in the Era of COVID: A comparison between media platforms
}

\author{
Dalia Almaghaslah \\ College of Pharmacy, King Khalid University, Saudi Arabia
}

\author{
Keywords \\ Blackboard \\ COVID-19 \\ Instagram \\ Online education \\ Pharmacy education \\ Twitter
}

\section{Correspondence}

Dalia Almaghaslah

Department of Clinical Pharmacy

College of Pharmacy

King Khalid University

Saudi Arabia

damoazle@kku.edu.sa

\begin{abstract}
Introduction: When it comes to using social media in pharmacy education, Facebook and Twitter are very popular. Methods: Instagram and Twitter accounts were created to complement formal teaching beyond core course hours in a fully online Communication in Pharmacy Practice course. The current study was conducted to assess students' perceptions of the incorporation of social media platforms in teaching the course. It provided a comparison between the use of Blackboard, Instagram and Twitter in course delivery. Results: Out of the total 70 students enrolled in the course, 67 students completed the online questionnaire. Blackboard was preferred for academic use (44 students, or $65.7 \%$ ), delivery of course announcements (36, or $53.7 \%)$, course core materials (34, or $50.7 \%)$ and provided the highest level of privacy (31, or $46.3 \%)$. On the other hand, Twitter was the most preferred for personal use (43, or $64.2 \%)$, delivery of extra-curricular materials (36, or $53.7 \%)$, discussion $(36$, or $53.7 \%)$, and was found to be the most convenient (62.7\%), user friendly (41, or $61.2 \%$ ) and provided the best notifications (alerts) (33, or $49.3 \%$ ). The vast majority "agreed" or "strongly agreed" that social media enhanced communication with peers $(52$, or $77.6 \%)$ and with the course instructor $(54$, or $80.6 \%)$. Conclusion: This evaluation demonstrated that students value social media use in teaching a fully online course, especially in the delivery of extra-curricular materials and discussions.
\end{abstract}

\section{Introduction}

Social media use has gained immense popularity worldwide (Chen and Divall, 2018). Social networking sites - such as Instagram, Facebook, Twitter, Tumblr, MySpace and Snapchat - continue to increase in users daily (Kukreja et al., 2011; Wright, Frame, \& Hartzler, 2014; Alamri, 2019). Social networking is defined by Kaplan and Haenlein (2010) as applications that use the internet and allow for the creating and sharing of usergenerated information. It has been suggested that social media has had a great influence on communication, exchanging information and staying up-to-date on the news (Chen and Divall, 2018).

Social media platforms are extremely popular in Saudi Arabia. A study by Dimitrios and Alali (2014) suggested that $85 \%$ of the Saudi population use social media heavily. The most common social media applications included Facebook, Twitter, YouTube, Google, LinkedIn and are used for education, entertainment and socialising, as well as for professional and marketing purposes. Another study suggested that, on average, Saudi people tend to use three to four social media applications, with Facebook and Twitter being the most popular. There were $95 \%$ of the participants accessed their social media accounts at least once a week, and more than half access them on a daily basis, with the 20-40 age group being the heaviest users. Communicating with family and friends was the top reason for using social media sites. Other important reasons included communicating about recent local or world news, engaging in social issues and knowledge transfer (Askool, 2013).

Using social media for academic purposes among Saudi undergraduate students was assessed by Alamri (2019). The study concluded that the perceptions of incorporating social media platforms in education were generally positive. A statistically significant relationship was found between social media usage and students' GPA. The most favoured applications were Twitter, WhatsApp, Snapchat and Instagram, whereas Facebook, Linkedln, Flicker and Wiki were the least preferred. 
Social media has often been used in pharmacy education (Desselle, 2017). Twitter has been used in pharmacy education for various purposes. Dvorkin Camiel and authors (2014) suggested that students regarded Twitter as a useful tool for sharing health news and developing personal learning networks. Fox and Varadarajan (2011) found that Twitter facilitated interactions between academic staff, students and guests in a pharmacy management course taught in two campuses at the same time. Wright, Frame and Hartzler (2014) assessed the use of Twitter and teambased learning in a self-care course and concluded that students found its use irrelevant and could not see its necessity. Desselle (2017) suggested that Twitter was a useful tool for students enrolled in a health systems course for self-directed supplementation of course material and continued engagement in a constructionist learning environment. Facebook use among pharmacy students has been evaluated in earlier literature. Mawdsley and Schafheutle (2015) concluded that using Facebook in teaching a disease management course was useful as an online social learning tool and for exam preparation. Similar findings were reported by Divall and Kirwin (2012), who indicated that adding a Facebook page in teaching a comprehensive disease management course was a valuable tool and contributed to students learning. The study by Estus (2010) was consistent with the findings of previous studies, where students regarded their experience of incorporating Facebook within a geriatric pharmacotherapy course to be positive and helpful in open discussions among class members. Cain and Policastri (2011) argued that having a Facebook page allowed experts in the field to contribute to the teaching of pharmacy management and leadership courses, through which the students could be exposed to real-world issues.

Bongartz and authors (2011) evaluated students' social interactions with academic staff through social media. They considered "friending" a faculty staff member to be violating a boundary; "tagging" them in photos was seen to be more acceptable. They concluded that keeping behaviour professional and setting boundaries was essential. Schneider and authors (2011) assessed the faculty members' perceptions of social interactions with their students. They also perceived "friending" on Facebook to be a boundary violation.

Kukreja, Heck Sheehan and Riggins (2011) assessed the use of social media among pharmacy preceptors. They found that Facebook was more popular among pharmacy preceptors than Twitter. Obtaining continuous education credits and following professional organisations were the two top reasons for using social media in professional practice.
The Ministry of Education in Saudi Arabia has responded to the COVID-19 pandemic by shifting faceto-face teaching and learning into fully online education in all educational institutions.

Synchronous Virtual Learning Environments (VLEs), such as Blackboard, have limited functionality and restricted uptake. Hence, learners are generally turning to social media applications to communicate about studies beyond the traditional institutional platforms. Modern students are familiar with digital technology, so it is important for educators to consider utilising these technologies in curriculum design and delivery (Mawdsley and Schafheutle, 2015). Since students are using social media as an informal, supportive tool in their studies, it is worth exploring whether and how the incorporation of Instagram and Twitter could support students in their education.

The current study was conducted to assess students' perceptions of the incorporation of social media platforms in teaching a fully online course: Communication Skills in Pharmacy Practice.

In the past, Blackboard has not been used by students, regardless of the efforts made by the course instructor. Students only participated in graded discussions. Access to the discussion board is limited across wireless technologies, such as tablet computers and smartphones. These discussion boards do not send notifications when content is added and so require students to deliberately check for updates. Instagram and Twitter could potentially overcome these technical limitations.

It provided a comparison between Blackboard, Instagram, and Twitter in terms of the delivery of announcements, course materials, extracurricular materials, discussions, privacy, convenience, userfriendliness, personal use, academic use and overall preference. Although many studies have assessed the use of Twitter in pharmacy education, no previous study has assessed the use of Instagram.

These two social media applications were chosen based on the findings of the study by Alamri (2019), which suggested that these two platforms are highly preferred among Saudi undergraduates.

\section{Methods}

Communication Skills in Pharmacy Practice is the only formal communication course in the PharmD curriculum at the college, but communication topics and exercises are re-emphasised in the therapeutic courses throughout the programme, especially in providing patient counselling. The two-credit hour 
course is taught to level seven (year four) PharmD students. The objective of the course is for students to understand the communication process and to demonstrate effective communication skills when dealing with patients and healthcare professionals, as well as when providing patients with education and counselling. Most of the required reading for the course is from Communication Skills in Pharmacy Practice Fifth edition. The content covered in the course is divided into 14 topics and is delivered fully online through the learning management system Blackboard . Lectures are recorded using Blackboard collaborate Ultra at the beginning of each week, i.e. two lectures per week. The course was taught by a single assistant professor from the Clinical Pharmacy department and was worth a total of 100 points. Table I provides details on the number of assignments and grading of the course. The social media activity was extra, and those who took part were awarded three bonus marks. A total of 70 students were enrolled on the course in the second semester of the academic year 2020/2019.

The course uses the virtual learning environment Blackboard for timetabling, sharing files and discussion forums. A Blackboard discussion board and course messages were open throughout the course. These features were provided for students to discuss the course content and as a mode of communication and support from the course instructor.

Table I: Course assignments and point values

\begin{tabular}{lll}
\hline Assignment & Mode of delivery & $\begin{array}{l}\text { Total point } \\
\text { value }\end{array}$ \\
\hline Online quiz & Blackboard & 10 \\
\hline Assignment one & Blackboard & 2.5 \\
\hline Assignment two & Blackboard & 2.5 \\
\hline $\begin{array}{l}\text { Blackboard discussion } \\
\text { thread }\end{array}$ & Blackboard & 5 \\
\hline Midterm exam & In class & \\
\hline $\begin{array}{l}\text { Final exam } \\
\text { Twitter and Instagram } \\
\text { participation }\end{array}$ & $\begin{array}{l}\text { Social media } \\
\text { accounts }\end{array}$ & $\begin{array}{l}\text { Three extra } \\
\text { marks }\end{array}$ \\
\hline Total & & $\mathbf{1 0 0}$ \\
\hline
\end{tabular}

\section{Framing interaction}

The social media activity was implemented out of a desire to give students a new opportunity to experience learning through social media and to interact virtually in this fully online course.

This alternative use of Twitter and Instagram was consistent with the nature of the course, a communication course, as well as the active learning objective of this course, and was implemented easily because all the students enrolled on the course had a smartphone with active accounts in the two social media applications which they regularly use, although never as part of an academic course.

Prior to the beginning of the semester, the lecturer created Instagram and Twitter accounts for this course, as well as a hashtag \#CPH547, the course code, to be used across the two social media platforms. Using Twitter was explained in detail by Fox and Varadarajan (2011).

In week one of the second semester, the accounts were launched, and students were asked to follow them. They were given instructions in the syllabus about what was expected of them in terms of participation. All posts/comments within the social media platforms had to be suitable, professional, and applicable to the purpose of the activity.

The accounts were created to engage students and to supplement the course content in order to complement formal teaching beyond core course hours. The applications aimed to help students in assessment preparation through web discussion of sample questions, lecture content, assigned reading, online resources and frequently asked questions. This was achieved through various methods, such as posting sample questions to enhance discussion, uploading, or linking to further online resources, including YouTube videos, images and documents. It was also used for announcements when a new lecture, assignment or discussion board was posted on Blackboard. Announcements for quiz and midterm - i.e. time, topics included, and other instructions - were posted on both Instagram and Twitter. Students' feedback on several aspects of the course was obtained regularly using Twitter poll features. However, they were not used as formal teaching tools.

For four weeks of the study, students were requested to participate on Twitter by commenting, liking, retweeting, taking part in a poll, or answering questions. Whereas participating on Instagram was through commenting, liking, or answering questions. Students were also encouraged to post using the hashtag \#CPH547. The instructor made sure to comment on all students' participation to encourage them further and to enhance student-instructor interactions.

The course instructor decided to make the accounts open, i.e. all Twitter and Instagram users could view and interact with the platforms' contents. Students were not obliged to follow the accounts to view the contents nor to receive notifications when new content was uploaded. The instructor did not follow any of the students back to maintain professional boundaries. 
The instructor made sure to post on both platforms at least five times when a new lecture was uploaded into Blackboard, such as questions, discussions, weblinks and videos, with different content in each platform and links to redirect students to the other platform. To encourage socialisation and further participation, the instructor initiated and prompted discussions among the students.

To provide an assessment of students' engagement in social media, the number of likes, comments, uses of the hashtag \#CPH547 and private messages were counted manually in the Instagram account. It was the same with Twitter account: the number of likes, comments, retweets, participation in polls, private messages and the use of the hashtag \#CPH547 was counted manually.

At the end of the four weeks, students were asked to complete an online questionnaire. Section one of the questionnaire collected demographic information and general information about social media use. Section two compared the use of Blackboard, Instagram and Twitter in terms of delivery of announcements, course materials, extracurricular materials, discussions, privacy, convenience, user-friendliness, personal use, academic use and preference. The third section of the questionnaire was composed of ten-item Likert scale questions using a five-point Likert scale, with one =strongly disagree and five=strongly agree. This was to assess students' experience of the incorporation of social media into the delivery of a fully online course.
Results were downloaded and stored in a Microsoft Excel spreadsheet. It was then transferred to SPSS version 26 for analysis. The results were described in terms of frequencies and percentages, and a chi-squared test was used to evaluate the differences for categorical data. A $p$-value less than 0.05 was considered significant.

\section{Ethics approval}

All respondents were asked for their consent before participation in the study.

\section{Results}

Table II shows that the number of students enrolled in the course was 70, the number of Twitter account holders was 73, and the number of Instagram account holders was 69. Four messages were received through Blackboard and through Twitter, while five messages were received through Instagram. A total of 453 and 1,740 "likes" were reported on Twitter and Instagram, respectively. A total of 8; 194; and 166 comments were reported on Blackboard, Twitter, and Instagram, respectively. The course hashtag $\mathrm{CPH} 547$ was used more often on Twitter (80 times) than on Instagram (69 times). Students voted in Twitter pools 250 times and retweeted some of the instructor's tweets 42 times.

Table II: Comparison of students' participation on Blackboard, Instagram, and Twitter

\begin{tabular}{|c|c|c|c|c|c|c|c|}
\hline & $\begin{array}{c}\text { Users/ } \\
\text { Followers }\end{array}$ & $\begin{array}{c}\text { Course } \\
\text { messages/ } \\
\text { private } \\
\text { messages }\end{array}$ & Likes & $\begin{array}{c}\text { Comments/ } \\
\text { discussion board }\end{array}$ & Hashtag & $\begin{array}{c}\text { Poll } \\
\text { voting }\end{array}$ & Retweet \\
\hline Blackboard & 70 & 4 & $\begin{array}{c}\text { Not } \\
\text { applicable }\end{array}$ & 8 & $\begin{array}{c}\text { Not } \\
\text { applicable }\end{array}$ & $\begin{array}{c}\text { Not } \\
\text { applicable }\end{array}$ & $\begin{array}{c}\text { Not } \\
\text { applicable }\end{array}$ \\
\hline Twitter & 73 & 4 & 453 & 194 & 80 & 250 & 42 \\
\hline Instagram & 69 & 7 & 1740 & 166 & 69 & $\begin{array}{c}\text { Not } \\
\text { applicable }\end{array}$ & $\begin{array}{c}\text { Not } \\
\text { applicable }\end{array}$ \\
\hline
\end{tabular}

Table III shows background information. Out of the total of 70 students enrolled on the course, 67 students completed the online questionnaire $(95.7 \%)$. Almost all the participants (64, or $95.5 \%$ ) were between the ages of 21 and $23, p=0.0001$. The vast majority said they used social media platforms daily $(56$, or $83.6 \%$ ), while just over half of them checked the course social media platforms daily (35, or $52.2 \%)$, and $29(43 \%)$ checked them several times per week, $p=0.0001 .26$ (38.8\%) of the students preferred the instructor to post on the course account in the evenings, whereas $13(19.4 \%)$ were indifferent about the time of posting, $p=0.003$.

Table IV shows the comparison of Instagram, Twitter and Blackboard use in teaching a fully online course. When comparing the use of social media platforms - i.e. Instagram, Twitter and Blackboard - Blackboard was preferred for: academic use (44 students, or $65.7 \%$ ), $p=0.0001$, delivery of course announcements $(36$, or $53.7 \%$ ), $p=0.0001$, course core materials (34, or $50.7 \%$ ), $p=0.002$, and providing the highest level of privacy (31, or $46.3 \%), p=0.0060 n$ the other hand, Twitter was the most preferred for: personal use (43, or $64.2 \%)$ $p=0.0001$, delivery of extra-curricular materials $(36$, or $53.7 \%$ ) $p=0.001$, discussion (36, or $53.7 \%$ ) $p=0.002$, and was found to be the most convenient $(42$, or $62.7 \%)$, $p=0.0001$, user friendly (41, or $61.2 \%) p=0.0001$ and provided the best notifications (alerts) (33, or $49.3 \%)$, $p=0.006$. 
Table III: Background information

\begin{tabular}{|c|c|c|c|}
\hline & $\begin{array}{c}\text { Number (\%); } \\
n=67\end{array}$ & $\mathrm{X}^{2}$ & $P$-value \\
\hline \multicolumn{4}{|l|}{ Age } \\
\hline$<21$ & $2(3)$ & 116.6 & 0.0001 \\
\hline $21-23$ & $64(95.5)$ & & \\
\hline$>23$ & $1(1.5)$ & & \\
\hline \multicolumn{4}{|c|}{ Frequency of checking social media } \\
\hline Daily & $56(83.6)$ & & 0.0001 \\
\hline Several times per week & $11(16.4)$ & & \\
\hline Several times per month & 0 & & \\
\hline \multicolumn{4}{|c|}{ Frequency of checking the course social media platforms } \\
\hline Daily & $35(52.2)$ & 56.6 & 0.0001 \\
\hline Several times per week & $29(43.3)$ & & \\
\hline Several times per month & $1(1.5)$ & & \\
\hline Only for assignments & 2(3) & & \\
\hline \multicolumn{4}{|c|}{ Time preferred by students for the instructor to post on social media } \\
\hline Morning 12-8 & $11(16.4)$ & 16.2 & 0.003 \\
\hline Afternoon 5-12 & 10(14.9) & & \\
\hline Evening 8-5 & $26(38.8)$ & & \\
\hline Night time $12-8$ & $7(10.4)$ & & \\
\hline Does not matter & $13(19.4)$ & 19.4 & \\
\hline
\end{tabular}

$p$-value $<0.05$ was statistically significant

Table IV: Comparison of Instagram, Twitter and Blackboard use in teaching a fully online course

\begin{tabular}{|c|c|c|c|c|c|c|}
\hline & $\begin{array}{c}\text { Instagram } \\
\text { n (\%) }\end{array}$ & $\begin{array}{c}\text { Twitter } \\
\text { n (\%) }\end{array}$ & $\begin{array}{c}\text { Blackboard } \\
\text { n (\%) }\end{array}$ & Total & $\mathrm{X}^{2}$ & $p$-value \\
\hline \multicolumn{7}{|l|}{ Delivery } \\
\hline Course announcements & 8 (11.9) & $23(34.3)$ & $36(53.7)$ & 67 & 17.582 & ${ }^{*} 0.0001$ \\
\hline Course materials (syllabus) & $10(14.9)$ & $23(34.3)$ & $34(50.7)$ & 67 & 12.925 & ${ }^{*} 0.002$ \\
\hline Extracurricular materials & $17(25.4)$ & $36(53.7)$ & $13(19.4)$ & 67 & 13.727 & ${ }^{*} 0.001$ \\
\hline Discussions & $15(22.4)$ & $36(53.7)$ & $16(23.9)$ & 67 & 12.56 & ${ }^{*} 0.002$ \\
\hline \multicolumn{7}{|l|}{ Features } \\
\hline Privacy & $18(26.9)$ & $17(25.4)$ & $31(46.3)$ & 67 & 5.54 & 0.062 \\
\hline Convenience (accessibility) & $16(23.9)$ & $42(62.7)$ & $8(11.9)$ & 67 & 28.7 & ${ }^{\star} 0.0001$ \\
\hline Notifications & $12(17.9)$ & $33(49.3)$ & $21(31.3)$ & 67 & 10.09 & 0.006 \\
\hline User friendly & $19(28.4)$ & $42(61.2)$ & $6(9)$ & 67 & 28.4 & ${ }^{*} 0.0001$ \\
\hline \multicolumn{7}{|l|}{ Preference } \\
\hline Personal preference & $17(25.4)$ & $43(64.2)$ & $7(10.4)$ & 67 & 30.9 & ${ }^{*} 0.0001$ \\
\hline Academic use & $3(4.5)$ & $20(29.9)$ & $44(65.7)$ & 67 & 38 & ${ }^{*} 0.0001$ \\
\hline
\end{tabular}

$* p$-value $<0.05$ was statistically significant

Table V shows students' overall satisfaction with the incorporation of social media. The vast majority $(58$, or $86.5 \%)$ of the students "agreed" or "strongly agreed" that the incorporation of social media in teaching a fully online course made studying fun, and just over half of them (34, or 50.8\%) "agreed" or "strongly agreed" that 
using social media reduced the time allotted for selfstudy. Additionally, the vast majority "agreed" or "strongly agreed" that social media enhanced communication with peers (52, or $77.6 \%)$, and with the course instructor (54, or $80.6 \%$ ). The majority of students (56, or 83.6\%) "agreed" or "strongly agreed" (56, or $83.6 \%$ ) that social media platforms facilitated sharing ideas among the class and helped them express their opinions $(50$, or $74.6 \%)$. The majority of participants (52, or 77.7\%) "agreed" or "strongly agreed" that question/answer posts were beneficial and 51 (or $77.6 \%$ ) felt that using social media helped in achieving the course objectives and was beneficial overall (51, or $76.1 \%)$. The majority of students $(50$, or $74.7 \%)$ "agreed" or "strongly agreed" that they would love to take other courses using the same strategy .

Table V: Students' overall satisfaction with the incorporation of social media in teaching a fully online course

\begin{tabular}{|c|c|c|c|c|c|}
\hline & \multicolumn{5}{|c|}{ Number of students (\%); $n=67$} \\
\hline & $\begin{array}{l}\text { Strongly } \\
\text { agree }\end{array}$ & Agree & Neutral & Disagree & $\begin{array}{l}\text { Strongly } \\
\text { disagree }\end{array}$ \\
\hline $\begin{array}{l}\text { I found that incorporating course materials } \\
\text { into social media made studying fun }\end{array}$ & $34(50.7)$ & $24(35.8)$ & $13(19.4)$ & & \\
\hline $\begin{array}{l}\text { I found that incorporating course materials } \\
\text { into social media reduced the time allotted for } \\
\text { self-study }\end{array}$ & $17(25.4)$ & $17(25.4)$ & $22(32.8)$ & $11(16.4)$ & \\
\hline $\begin{array}{l}\text { I found that using social media in the course } \\
\text { enhanced my communication with peers }\end{array}$ & $24(35.8)$ & $28(41.8)$ & $13(19.4)$ & $2(3)$ & \\
\hline $\begin{array}{l}\text { I found using social media in the course } \\
\text { enhanced my communication with the course } \\
\text { instructor }\end{array}$ & $34(50.7)$ & 20 (29.9) & 12 (17.9) & $1(1.5)$ & \\
\hline $\begin{array}{l}\text { I found question/answer posts beneficial to } \\
\text { learn material }\end{array}$ & $23(47.8)$ & $20(29.9)$ & 12 (17.9) & $1(1.5)$ & \\
\hline $\begin{array}{l}\text { I found using Instagram and Twitter facilitated } \\
\text { sharing ideas among the class }\end{array}$ & $36(53.7)$ & 20 (29.9) & 8 (11.9) & $2(3)$ & \\
\hline $\begin{array}{l}\text { I found that using social media helped me to } \\
\text { express my opinion when I would not } \\
\text { otherwise have expressed it in class }\end{array}$ & $28(41.8)$ & $22(32.8)$ & $13(19.4)$ & $3(4.5)$ & \\
\hline $\begin{array}{l}\text { I found incorporation of course material } \\
\text { helped in meeting the course objectives }\end{array}$ & $28(41.8)$ & $24(35.8)$ & $15(22.4)$ & & \\
\hline $\begin{array}{l}\text { I found using Instagram and Twitter in the } \\
\text { course was beneficial overall }\end{array}$ & $30(44.8)$ & $21(31.3)$ & $13(19.4)$ & $3(4.5)$ & \\
\hline $\begin{array}{l}\text { I'd love to take another course using the same } \\
\text { mode of communication }\end{array}$ & $31(46.3)$ & $19(28.4)$ & $14(20.9)$ & $2(3)$ & $1(1.5)$ \\
\hline
\end{tabular}

\section{Discussion}

The COVID-19 pandemic has affected education by closing all educational institutions, suspending face-toface in-class teaching and learning, and shifting to online education (Almaghaslah \& Alsayari, 2020). Hence, online education has become the primary mode of education. Most Saudi universities, including KKU, use virtual learning environments such as Blackboard for the electronic delivery of courses. Social media, however, is not officially utilised in education (Almaghaslah \& Alsayari, 2020).

Learners use social media to communicate about their studies (Mawdsley and Schafheutle, 2015). This is the first study that has assessed students' perceptions of incorporating social media platforms in teaching a fully-online pharmacy course - Communication Skills in Pharmacy Practice. It also provides a comparison between Blackboard, Instagram and Twitter in terms of their use in course delivery. In this study, students revealed heavy use of social media in their everyday lives, as well as for learning. It supports the literature confirming that students are positive about the use of social media in education and demonstrates that, for pharmacy students, engaging in virtual social learning helped in the achievement of the course's learning objectives and was beneficial overall (Kaplan \& 
Haenlein, 2010; Bongartz et al., 2011; Dvorkin Camiel et al., 2014; Desselle, 2017).

Not only this, but it also made studying an enjoyable task and reduced the time allotted for self-study.

In spite of the benefits to students' learning, this study also revealed similar findings to previous research, in particular, concerns over personal privacy and crossing professional boundaries (Bongartz et al., 2011; Schneider et al., 2011). This is evident, as almost half of the participants found that the virtual learning environment Blackboard provided had the highest levels of privacy and was still preferred for academic use, such as the delivery of the course core-curricular materials and announcements. However, social media applications - Twitter in particular - were found to be more convenient and user friendly and to have a better notification (alerts) feature; hence it was preferred for the delivery of extracurricular materials and discussions. Students revealed that Twitter was their preferred application for personal use; hence they did not use it as much as Instagram for academic purposes. Instagram posts recorded almost double the number of private messages and likes compared to Twitter. Since all the students were using their personal accounts, bearing in mind they preferred Twitter; they were more likely to keep their personal privacy by not participating on Twitter as much as they did on Instagram, to avoid the awkward connection between private and professional life. Having said that, Twitter was still very useful because of its unique features, i.e. retweet and poll votes, which were lacking on Instagram. Therefore, by using both platforms simultaneously, they complemented each other.

The successful incorporation of social media in teaching requires applying academic judgment in deciding the content: core curricular vs extracurricular, assessment, summative vs formative, time of delivery, morning vs evening, and platform - Blackboard versus Instagram and Twitter.

In this study, social media was preferred for formative assessment to be posted in the evenings between five and eight pm, and Twitter was more popular among students, although a minority still preferred Instagram.

Students found peer communication valuable, and communication with the instructor was appreciated as it demonstrated enhanced student-teacher relationships. A previous study conducted on using online learning among undergraduate pharmacy students in Saudi Arabia revealed that students still preferred communicating with the course instructor in person, during office hours, when social media was not utilised in fully online courses, hence having social media platforms could be an effective alternative mode of communication between students and instructors
(Almaghasla et al., 2018). This study also found that the incorporation of social media helped students express their opinions when they would not otherwise have expressed them in class. Almaghaslah and authors (2018) also explained how students fear being exposed during in-class discussions and interactive activities; hence using social media provides reassurance and the security to express their opinion in a virtual environment without feeling that they have been put on the spot.

This echoes previous work on how social media has a positive impact on peer interaction, expressing opinions and sharing ideas in class (Fox and Varadarajan, 2011).

When asked about whether they preferred to take other courses with social media incorporated, the majority "agreed" or "strongly agreed", demonstrating that the student's overall experience was positive.

Increasing learner involvement and immersion in the learning environment is crucial in pharmacy education because of the demand for a higher order of thinking within the pharmacy profession. Educators need to incorporate more engaging tools, such as social media platforms, into the pharmacy curriculum to foster the required skills and other required learning outcomes in students (Seybert \& Kane-Gill, 2011). In this context, this will help in changing students' learning autonomy to more self-directed learning and will probably enhance their participation and engagement in their learning journey

This study has several limitations. The questionnaire focused only on two social media platforms out of many preferred among Saudi undergraduate students. Additionally, the study focused on students' perceptions of teaching a fully online course using our virtual learning environment (Blackboard). Saudi students' learning styles are different from those in more developed nations. Therefore, these teaching strategies might be generalisable only to other schools that have students with a similar learning style, using similar virtual learning environments and having similar preferences when it comes to social media platforms.

\section{Conclusion}

This exploratory study showed that the incorporation of social media platforms - i.e. Instagram and Twitter to engage students and supplement the course content, as well as to complement formal teaching beyond core course hours, was generally positive. It also enhanced communication with peers and with the course instructor, as well as facilitated the sharing of ideas and opinions in the class. Since virtual learning 
environments, such as the Blackboard platform, were found less useful in achieving student engagement, pharmacy instructors should adopt social learning in their curricula design by considering social media. Other aspects to consider are what social media applications to use, what content to post and at what time, as well as how to assess this content.

\section{References}

Alamri, M. M. (2019) 'Undergraduate students' perceptions toward social media usage and academic performance: A study from Saudi Arabia', International Journal of Emerging Technologies in Learning, 14(3), pp. 61-79. https://doi.org/10.3991/ijet.v14i03.9340

Almaghaslah, D.et al. (2018) 'Pharmacy students' perceptions towards online learning in a Saudi Pharmacy School', Saudi Pharmaceutical Journal. https://doi.org/10.1016/j.jsps.2018.03.001

Almaghaslah D, Alsayari A. (2020). The effects of the 2019 novel coronavirus disease (COVID-19) outbreak on academic staff members: A case study of a pharmacy school in Saudi Arabia. Risk Manag Health Policy. https://doi.org/10.2147/RMHP.S260918

Askool, S. S. (2013) 'The use of social media in Arab countries: A case of Saudi Arabia', in Lecture Notes in Business Information Processing, pp. 201-219. https://doi.org/10.1007/978-3-64236608-6_13

Bongartz, J.et al. (2011) 'Student pharmacist, pharmacy resident, and graduate student perceptions of social interactions with faculty members.', American Journal of Pharmaceutical Education. https://doi.org/10.5688/ajpe759180

Cain, J. and Policastri, A. (2011) 'Using facebook as an informal learning environment', American Journal of Pharmaceutical Education. https://doi.org/10.5688/ajpe7510207

Chen, E. and Divall, M. (2018) 'Social media as an engagement tool for schools and colleges of pharmacy', American Journal of Pharmaceutical Education, 82(4), pp. 354-364. https://doi.org/10.5688/ajpe6562

Desselle, S. P. (2017) 'The use of Twitter to facilitate engagement and reflection in a constructionist learning environment', Currents in Pharmacy Teaching and Learning. Elsevier, 9(2), pp. 185-194. https://doi.org/10.1016/j.cptl.2016.11.016

Dimitrios, X. and Alali, (2014) 'Investigating the attitude of the average Saudi towards the Social Media', (May 2014), pp. 86-94. https://doi.org/10.1109/ICIST.2014.6920546

Divall, M. V. and Kirwin, J. L. (2012) 'Using facebook to facilitate course-related discussion between students and faculty members', American Journal of Pharmaceutical Education. https://doi.org/10.5688/ajpe76232

Dvorkin Camiel, L. et al. (2014) 'Twitter as a medium for pharmacy students' personal learning network development', Currents in
Pharmacy Teaching and Learning. Elsevier, 6(4), pp. 463-470. https://doi.org/10.1016/j.cptl.2014.04.008

Estus, E. L. (2010) 'Using facebook within a geriatric pharmacotherapy course', American Journal of Pharmaceutical Education. https://doi.org/10.5688/aj7408145

Fox, B. I. and Varadarajan, R. (2011) 'Use of twitter to encourage interaction in a multi-campus pharmacy management course', American Journal of Pharmaceutical Education, 75(5). https://doi.org/10.5688/ajpe75588

Kaplan, A. M. and Haenlein, M. (2010) 'Users of the world, unite! The challenges and opportunities of Social Media', Business Horizons. https://doi.org/10.1016/j.bushor.2009.09.003

Kukreja, P., Heck Sheehan, A. and Riggins, J. (2011) 'Use of social media by pharmacy preceptors.', American Journal of Pharmaceutical Education, 75(9), p. 176. https://doi.org/10.5688/ajpe759176

Mawdsley, A. and Schafheutle, E. I. (2015) 'Using Facebook to support learning and exam preparation in a final-year undergraduate pharmacy clinical therapeutics module', Currents in Pharmacy Teaching and Learning. Elsevier, 7(6), pp. 869-875. https://doi.org/10.1016/j.cptl.2015.08.010

Schneider, E. F. et al. (2011) 'Faculty perceptions of appropriate faculty behaviors in social interactions with student pharmacists', American Journal of Pharmaceutical Education. https://doi.org/10.5688/ajpe75470

Seybert, A. L. and Kane-Gill, S. L. (2011) 'Elective course in acute care using online learning and patient simulation', American Journal of Pharmaceutical Education. https://doi.org/10.5688/ajpe75354

Wright, K. J., Frame, T. R. and Hartzler, M. L. (2014) 'Student perceptions of a Self-Care course taught exclusively by team-based learning and utilizing Twitter', Currents in Pharmacy Teaching and Learning. https://doi.org/10.1016/j.cptl.2014.07.003 